\title{
EVALUATION OF INDIVIDUAL MEMBERS IN ENGINEERING DESIGN TEAMS
}

\author{
Michel F. Couturier and Guida Bendrich \\ Department of Chemical Engineering, University of New Brunswick \\ cout@unb.ca
}

\begin{abstract}
The curriculum of accredited engineering programs in Canada must culminate with a significant design experience where students must demonstrate an ability to work in teams. The determination of individual grades for work products submitted by a team is however a challenging task. To deter students from free riding on the efforts of their teammates, every team member should not simply receive the same grade. Individual grades in the senior process design course at the University of New Brunswick are determined by first assigning a team grade to team deliverables and then adjusting each team member's grade up or down using a multiplier. The value of the multiplier is based on peer and mentor evaluations and on the level of participation of the student in course activities. The peer ratings collected in 2014-2015 are generally higher than the mentor ratings, likely because of peer pressures to give high ratings. The bias is greatly reduced however when the evaluations are normalized by dividing the rating for each student by the team average. Because of this bias, the mentor evaluations should complement the peer ratings when providing formative feedback to students and determining individual team member grades.
\end{abstract}

Keywords: peer evaluation, teamwork, assessment factor, grade adjustment

\section{INTRODUCTION}

Engineering programs normally include a final-year design course in which teams of four or more students must complete a significant design project. The determination of individual grades in a project-oriented course with no midterm or final exam is challenging when all tasks are completed in a team setting outside of class. Peer assessment is normally used to arrive at individual grades in this context. The argument for using peer evaluation to adjust student grades is that team members are better able to observe and evaluate members' contributions than are instructors, who see outcomes but not the behind-the-scene process [1]. Peer evaluations also reduce free riding by increasing students' accountability to their teammates [2]. However, solidarity within the teams is strong and ratings provided by peer evaluations are generally high unless conflicts exist within the team.

To arrive at more accurate individual evaluations, additional performance assessment tools are used in the full-year capstone plant design course in the Chemical Engineering program at UNB. Individual grades are determined by first assigning a team grade to team deliverables and then adjusting each team member's grade up or down using a multiplier. The value of the multiplier is based on peer ratings, on the level of participation of the student in course activities and also on the evaluations of the student's contribution by the team co-mentors. A survey was developed in Microsoft Excel to collect data on team-member effectiveness. Students and co-mentors are asked to complete the survey at the course mid-point and again at the end of the year. The average results of the mid-point survey are shared with individual students as formative feedback on their performance. Information used by co-mentors to assess individual contributions includes discussions with students at weekly team meetings, periodic team deliverables, logbooks submitted monthly by each student, and average peer assessment results. In this paper, we provide more details regarding the structure of the course, the surveys and the calculation of the multiplier, and describe our experience with this method for assigning individual grades.

\section{ASSESSMENT METHOD}

\subsection{Course Structure}

A collaborative approach is used for teaching the capstone design course ChE 4225 Chemical Plant Design in the Chemical Engineering Department at the University of New Brunswick since 2010 [3]. Design projects undertaken in the course are sponsored by outside clients. Two teams of four or five students are assigned to each project. We let the students choose their teammates and the project on which they prefer to work. Brief project 
descriptions are provided to the students at the start of the year to guide their selection. The two teams assigned to each project work independently and are co-mentored by a faculty member and a practicing engineer. This collaborative approach brings engineering practice in the classroom while keeping faculty members in control of academic requirements. Co-mentors are expected to meet independently with each team under their responsibility for one hour every week and to provide written feedback on the milestone reports submitted every three weeks by the students. Funding for the industrial co-mentors is provided by the NSERC-UNB Chair for Collaborative Engineering Design Education held by one of the coauthors (M. Couturier).

The two course coordinators (M. Couturier and G. Bendrich) ensure that all groups are progressing at the same rate and are evaluated against the same criteria by setting eight evenly-spaced milestones (four per term) that all teams must complete. The outline for each milestone defines the tasks that need to be accomplished and set the marking scheme that will be used by the co-mentors to evaluate the deliverables. Feedback provided by the comentors on each milestone report is used by the students to improve their design and polish the written submission. Further gains in efficiency are obtained by asking students to format their written submissions as sections of the final report. In this manner, each submission is a new draft version of the final report. It includes a new section summarizing the work completed over the previous three weeks along with the sections that were previously submitted and recently updated using co-mentor feedback. The milestones and weekly meetings with co-mentors effectively pace and guide the students through the solution of their design problem while providing the framework for the progressive assembly of a high-quality final report for the client. We aim to have all teams produce a final report of the quality expected from engineers working in industry.

Design review meetings take place with the clients in November and February. These meetings start with an oral presentation by the students to update their client on their progress and conclude with questions and feedback from the client. The design work of the students is also showcased at our annual Engineering Design Symposium held in early April. All clients are invited to this celebration where the teams present an overview of their work.

\subsection{Student Evaluation}

The breakdown of the final grade of the students is provided in Table 1. The final report has the largest weighting because it is the main product of the design exercise and the only document given to the client. Each milestone report is only worth $5 \%$ of the overall mark
(Table 1). The students are therefore not heavily penalized if they make mistakes while completing the milestone tasks. It is important however that they learn from their mistakes and incorporate the feedback provided by the co-mentors in their draft report in order to do well on the final report. The path followed by the students is secondary as long as the client deliverables (final report and presentations) are of high quality.

Table 1: Breakdown of the final grade

\begin{tabular}{|c|c|}
\hline Deliverable & Value \\
\hline 1. Final report & $45 \%$ \\
\hline 2. First 7 milestones & $35 \%$ \\
\hline 3. 3 presentations & $20 \%$ \\
\hline
\end{tabular}

Students are individually evaluated during the presentations and their team grades on milestones are adjusted for individual performances using the following equation.

$$
\begin{gathered}
\text { Individual Mark } \\
\text { on Milestone }
\end{gathered}=\underset{\text { of }}{\text { x Group Mark }}
$$

The correction factor $\mathrm{CF}$, which can be greater or smaller than unity, takes into account the teammate and co-mentor evaluations and the participation of the student in the course.

$\mathrm{CF}=0.2 * \mathrm{CF}_{\text {participation }}+0.2 * \mathrm{CF}_{\text {co-mentor }}+0.6 * \mathrm{CF}_{\text {peer }}$

The active participation of every student is required to make the course Chemical Plant Design a positive experience for everyone. The students are expected to attend the weekly two-hour lectures (attendance is recorded) and to submit the following information:

- monthly logbooks which list the main tasks accomplished by the student and the time spent on each task,

- self and peer evaluations at the end of the fall and winter terms.

If the student misses no more than $30 \%$ of the lectures per term and submits all required information, $\mathrm{CF}_{\text {participation }}$ is assigned a value of unity; otherwise it takes on a value of zero.

The peer and co-mentor evaluations collected at the end of each term are used to calculate the assessment factors $\mathrm{CF}_{\text {co-mentor }}$ and $\mathrm{CF}_{\text {peer }}$ as follows,

$$
\begin{aligned}
& \mathrm{CF}_{\text {co-mentor }}=\underline{\text { Student's evaluation by co-mentors in } \%} \\
& \text { Avg of co-mentor evaluations for the group in } \% \\
& \mathrm{CF}_{\text {peer }}=\frac{\text { Student's evaluation by peers in } \%}{\text { Average of peer evaluations for the group in } \%}
\end{aligned}
$$


If the average evaluation received by the student from his/her peers is greater than the average of the evaluations received by all members of the group, $\mathrm{CF}_{\text {peer }}$ is greater than unity; otherwise it is less than unity. The same applies to $\mathrm{CF}_{\text {co-mentor }}$ which is derived from the evaluations provided by the co-mentors.

The correction factor CF is calculated at the end of the fall term and used to calculate the individual marks for milestones 1 to 4 . The correction factor is again calculated at the end of the winter term and used to obtain individual marks for milestones 5 to 7 . The average of the two correction factors is then used to determine the individual marks of the students on the final report using the following formula.

Individual Mark $=\left(\underline{\mathrm{CF}}_{\text {fall }}+\mathrm{CF}_{\text {winter }}\right) *$ Group Mark

$$
\text { on Final Report } 2 \text { on Final Report }
$$

\subsection{Peer and Co-mentor Evaluations}

At the end of the fall and winter terms, each team member must perform a self-evaluation and must evaluate his/her teammates using a survey developed in Microsoft Excel. The survey measures the sixteen team member attributes listed in Table 2. The attributes are divided into five general areas as suggested by Ohland et al. [1] and attempt to measure the quantity and quality of individual work as well as the teamwork skills of students. Each attribute is evaluated using a pull-down rubric which contains four levels from poor to excellent. The levels are assigned scores of $0 \%$ (poor), $50 \%$ (marginal), $75 \%$ (satisfactory), and $100 \%$ (excellent) for averaging purposes. The survey is sent to the students by email and the completed surveys are returned to the instructors by the same method. The scores provided by peers for each attribute are averaged and the overall average of the sixteen attributes for each student is used in Eq. 4 to calculate $\mathrm{CF}_{\text {peer }}$.

After the peer evaluations have been completed, the co-mentors are also asked to complete an evaluation of the students under their responsibility. Their survey is similar in structure to the one used by the students but measures fewer team member attributes or behaviors as shown in Table 3. The attributes which require information that only peers are in a position to observe are not evaluated by co-mentors. Information used by co-mentors to assess individual contributions includes the average peer assessment results, discussions with students at weekly team meetings, the logbooks submitted monthly by each student, and the milestone reports. The scores provided by the two co-mentors are averaged for each student and used in Eq. 3 to calculate $\mathrm{CF}_{\text {co-mentor }}$.

In addition to being used for adjusting team grades, the evaluations performed in late November are also shared with the students as formative feedback on their performance. To maintain the anonymity of the evaluators, only the aggregated peer and co-mentor results for each attribute are given to the students.

Table 2: Attributes assessed by peers

\begin{tabular}{|c|c|}
\hline Area & Attribute \\
\hline $\begin{array}{l}\text { 1. Contribution to team } \\
\text { work }\end{array}$ & $\begin{array}{ll}\text { - } & \text { interest in work } \\
\text { - } & \text { initiative } \\
\text { - } & \text { quantity of work } \\
\end{array}$ \\
\hline $\begin{array}{l}\text { 2. Interaction with } \\
\text { teammates }\end{array}$ & $\begin{array}{ll}\text { - } & \text { dependability } \\
\text { - } & \text { interpersonal behavior } \\
\text { - } & \text { conflict resolution } \\
\end{array}$ \\
\hline 3. Leadership & $\begin{array}{ll}\text { - } & \text { planning \& organizing } \\
\text { - } & \text { setting goals } \\
\text { - } & \text { leadership qualities } \\
\end{array}$ \\
\hline 4. Quality expectations & $\begin{array}{ll}- & \text { quality of work } \\
\text { - } & \text { creativity } \\
\text { - } & \text { judgement } \\
\end{array}$ \\
\hline 5. Skills & $\begin{array}{ll}\text { - } & \text { written communication } \\
\text { - } & \text { oral communication } \\
\text { - } & \text { integration of prior } \\
& \text { learning } \\
\text { - } & \text { problem solving skills } \\
\end{array}$ \\
\hline
\end{tabular}

Table 3: Attributes assessed by co-mentors

\begin{tabular}{|ll|ll|}
\hline \multicolumn{2}{|c|}{ Area } & \multicolumn{1}{c|}{ Attribute } \\
\hline 1. & $\begin{array}{l}\text { Contribution to team } \\
\text { work }\end{array}$ & $\bullet$ & attitude toward project \\
\hline 2. & $\begin{array}{l}\text { Interaction with } \\
\text { teammates }\end{array}$ & $\bullet$ & $\begin{array}{l}\text { dependability and } \\
\text { punctuality }\end{array}$ \\
& & $\bullet$ & team work \\
\hline 3. & Leadership & $\bullet$ & leadership qualities \\
\hline 4. & Quality expectations & $\bullet$ & quality of work \\
& & $\bullet$ & creativity \\
\hline 5. & Skills & $\bullet$ & problem solving skills \\
& & $\bullet$ & written communication \\
& & & technical knowledge \\
\hline
\end{tabular}

\section{RESULTS AND DISCUSSION}

\subsection{Correlation between Ratings}

The results of the surveys performed in November 2014 are presented in this section. A total of 53 students were evaluated. The students were divided into 12 teams (five teams of 5 students and seven teams of 4 students). Each student was therefore evaluated by two co-mentors and 3 or 4 peers. Six faculty members and 6 practicing engineers acted as co-mentors. 
The self-evaluation of each student (average of ratings for the 16 attributes) is plotted versus the average of his/her peer evaluations in Fig. 1. The results are generally grouped around the 45 degree line but the scatter is large. It is particularly important to note that students who obtained an average score less than $75 \%$ from their peers tended to overestimate their performance. This is in agreement with published findings which indicate that people with poor teamwork skills tend to overestimate their own abilities and contributions to the team because they are often unable to recognize their deficiencies [1]. Self-appraisals are used in ChE 4225 to encourage students to reflect on their performance but are not used to adjust team grades because they are vulnerable to leniency errors.

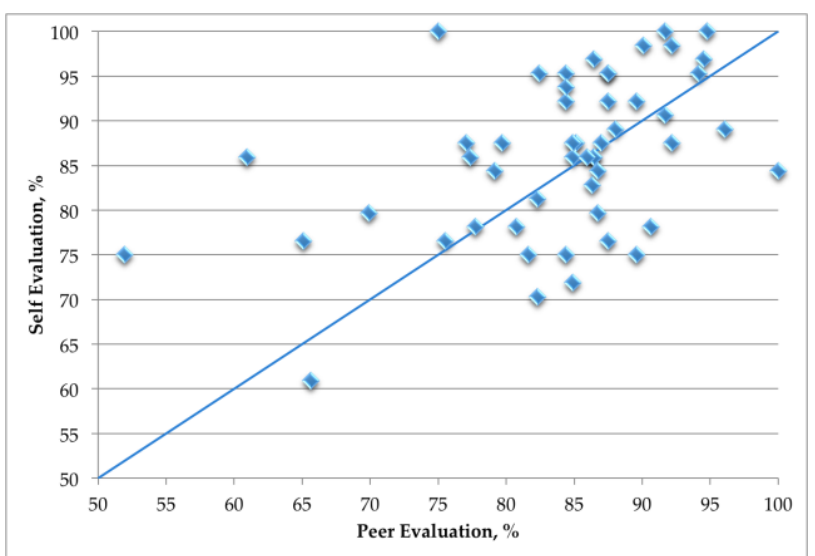

Fig. 1. Overall self-evaluation vs. avg. peer evaluation

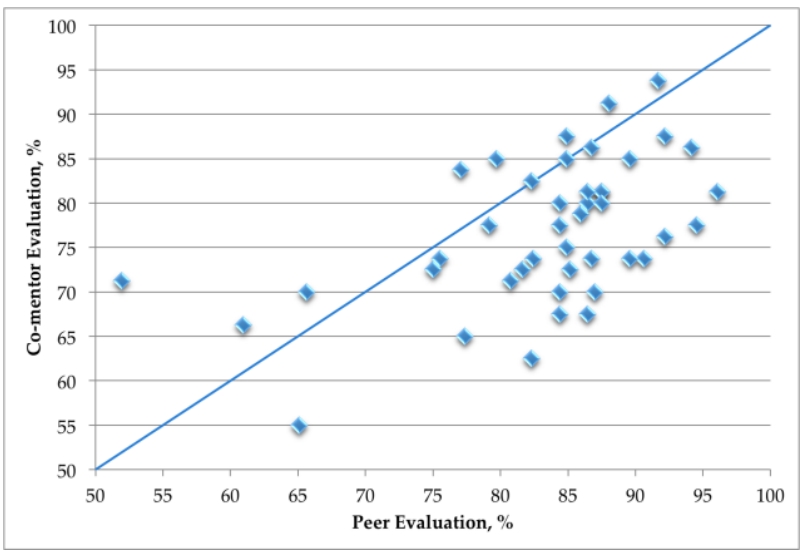

Fig. 2. Co-mentor evaluation vs. peer evaluation

The average of the two co-mentor evaluations for each student is plotted versus the average of the peer evaluations for the same students in Fig. 2. The fact that the majority of the data points are below the 45 degree line indicate that peer evaluations are generally higher than co-mentor evaluations. This is likely because some students worry that providing accurate ratings will create conflicts with teammates and therefore experience social pressures to give high ratings [1]. According to our experience, students generally receive high ratings from their peers unless their performance falls seriously below the group's expectations. In spite of these limitations, peer evaluations are useful tools to assess students' teamwork contributions because they increase students' accountability to their teammates and reduce hitch hiking [2]. Our findings nevertheless indicate that peer ratings should be complemented by instructor evaluations in order to provide accurate formative feedback to students.

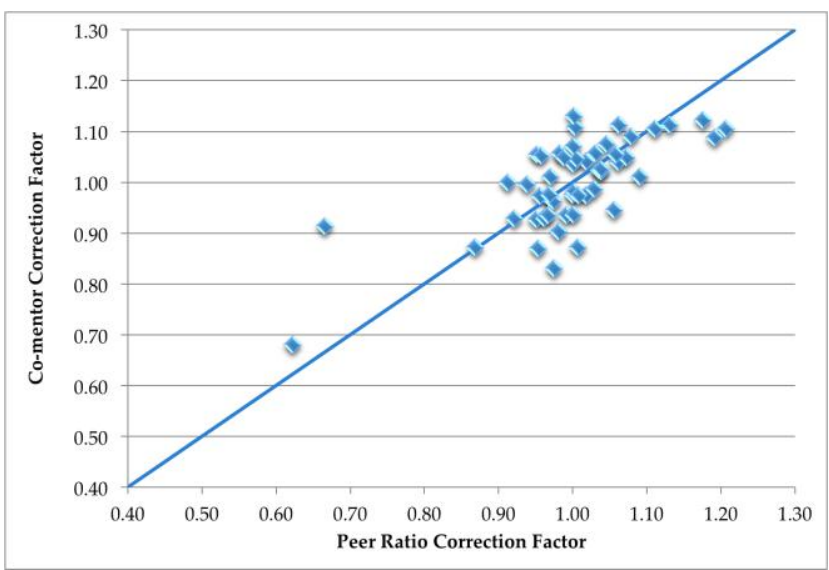

Fig. 3. $\mathrm{CF}_{\text {co-mentor }}$ versus $\mathrm{CF}_{\text {peer }}$

When the evaluations are normalized by dividing the average assessment for each student by the team average, biases in peer ratings appear to be eliminated and a good correlation is obtained between the co-mentor and peer assessment factors, $\mathrm{CF}_{\text {co-mentor }}$ and $\mathrm{CF}_{\text {peer }}$, as can be seen in Fig. 3. It is interesting to note that the majority of the values for the two assessment factors are between 0.9 and 1.1 in this case. This suggests that co-mentors and peers consider that team members are working well together and that there is little variation in team member performance within the teams. The students with assessment factors less than 0.9 are usually individuals who are not contributing effectively to their team. We find that the comentor and peer evaluations are useful tools for quickly drawing our attention to problematic team members.

The peer and co-mentor assessment factors are combined in equation 2 along with a participation factor to obtain the multiplier $\mathrm{CF}$ which is used to adjust the milestone and final report grades of each student. Because the factor with the largest weighting in equation 2 is $\mathrm{CF}_{\text {peer }}$ and because there is a strong correlation between the peer and co-mentor assessment factors (Fig. 3), there is also a strong correlation between the multiplier $\mathrm{CF}$ and the assessment factor $\mathrm{CF}_{\text {peer }}$ as can be seen in Fig. 4. This strong correlation suggests that the grade of most students could be adjusted simply by using the peer assessment factor $\mathrm{CF}_{\text {peer }}$ instead of the comprehensive multiplier $\mathrm{CF}$. This would however remove the incentive to participate in 
ancillary course activities. It would also remove the dampening effect provided by $\mathrm{CF}_{\text {co-mentor }}$ on unwarranted large deviations from unity of the peer assessment factor $\mathrm{CF}_{\text {peer }}$. Large deviations in $\mathrm{CF}_{\text {peer }}$ occur in dysfunctional teams where ratings can be biased by jealousy, revenge or discrimination.

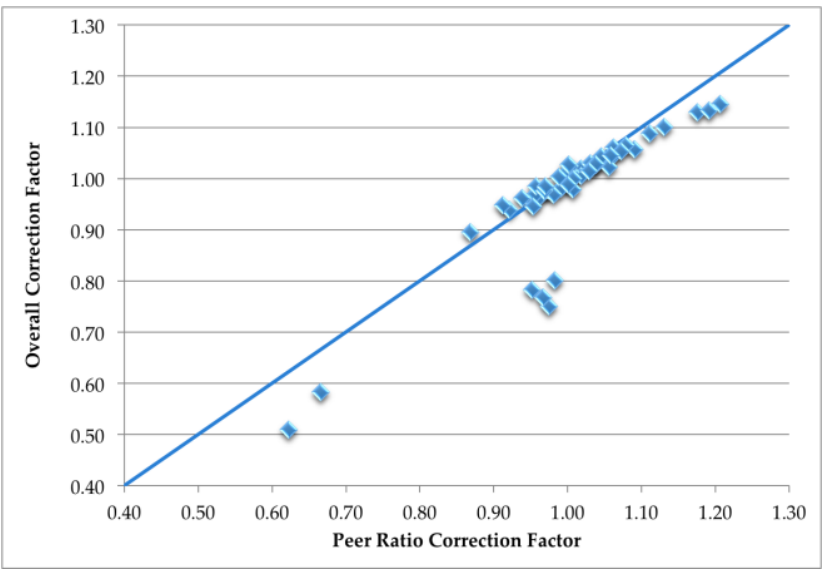

Fig. 4. Overall multiplier CF vs. $\mathrm{CF}_{\text {peer }}$

Since the majority of the values for the multiplier CF are between 0.9 and 1.1 , most students get an individual grade which is within $10 \%$ of their team grade. It would be erroneous to conclude from this that grade adjustment is not necessary. The grade adjustment can be large for members who do not contribute effectively to their team and this is a major deterrent for students who may consider free riding on the efforts of teammates or may decide to not participate in ancillary course activities.

\subsection{Experience Gained and Future Plans}

Because ChE 4225 is a project-oriented course with no midterm or final exam, assigning fair grades to students based on their individual contributions is a significant challenge. When we first started co-instructing the course in 2010, we gave every team member the same grade on milestone reports. This did not require any additional work on our part aside from marking the reports but rewarded and even encouraged free riding by some team members. We therefore started conducting a peer survey at the end of the year and took individual contributions into account by adjusting final report grades using a multiplier similar to the one proposed by Fink [2]. The administration of the original paper survey was however time consuming and we still had free riders who did not participate in ancillary course activities and benefitted from getting their group mark on milestones. These individuals were affecting team morale.

We replaced the paper survey by the current electronic survey in 2013. The electronic survey developed in Excel has greatly reduced the time required to collect and analyze the rating data. Instructors no longer need to reenter the data to calculate averages and the adjustment factors are calculated automatically. This new tool has made it possible to run the survey more often and to create a co-mentor survey. We therefore modified the calculation of the multiplier to include co-mentor ratings and class participation in 2014, and are now using the multiplier to adjust the grade of all team deliverables.

Ineffective team work is usually the main cause of poor student performance in ChE 4225 [3]. We try to detect team problems early using peer assessments in order to help students dissipate conflicts before they become too big. In the past two years, about $50 \%$ of the groups in ChE 4225 were effective teams, 30 to $40 \%$ of the teams had some issues and 10 to $20 \%$ of the teams experienced significant difficulties.

We feel that we have developed a good system for encouraging students to become effective team members and to evaluate individual team member contributions. We also believe that the milestone reports and design reviews with clients are effective methods for providing feedback to students on their design work. To further improve the experience of the students in the course, we plan to provide more frequent feedback to students on their team work by collecting peer and co-mentor ratings twice per term. This may require that we shorten the surveys using an approach similar to the one proposed by Ohland et al. [1]. Currently, it takes students about 30 minutes to fill out the survey for a four member team.

\section{CONCLUSIONS}

The success of team design projects depends on the ability of group members to work effectively as a team. If a member is not willing to put forth the effort to complete the assigned tasks, then the project will suffer and team members will not have a good experience in the course. It is important to evaluate individual team member contributions in order to provide developmental feedback, assign fair grades and to deter students from free riding on the efforts of teammates. Because peers often inflate their ratings to avoid conflicts with teammates, instructor evaluations should complement peer ratings to provide accurate formative feedback to students.

Individual grades in the design course ChE 4225 at UNB are determined by first assigning a team grade to team deliverables and then adjusting each team member's grade up or down using a multiplier. The value of the multiplier is based on peer ratings, on the level of participation of the student in course activities and also on the evaluations of the student's contribution by the team co-mentors. This approach for adjusting team grades to reflect individual contributions is more comprehensive than Fink's multiplier method [2] which is based solely on peer evaluations. 


\section{Acknowledgements}

Funding received from the Natural Sciences and Engineering Research Council of Canada for the NSERCUNB Chair for Collaborative Engineering Design Education is gratefully acknowledged. The authors are also grateful to the faculty and industrial co-mentors who have contributed to ChE 4225 between 2010 and 2015.

\section{References}

[1] Matthew W. Ohland, Misty L. Loughry, David J. Woehr, Lisa G. Gullard, Richard M. Felder, Cynthia J. Finelli, Richarch A. Layton, Hal R. Pomeranz, and Douglas G. Schmucker, "The Comprehensive Assessment of Team
Member Effectiveness: Development of a Behaviorally Anchored Rating Scale for Self- and Peer Evaluation," Academy of Management Learning \& Education, vol. 11, no. 4, pp. 609-630, 2012.

[2] Larry K. Michaelson, Arletta B. Knight, and L. Dee Fink, Team-based Learning: A Transformative Use of Small Groups. Westport, CT: Praeger Publishers, 2002, 288 pp. \{ISBN: 0-89789-863-X\}

[3] Michel F. Couturier, and Guida Bendrich, "Collaborative Approach for Teaching Chemical Process Design," in Proc. CEEA Canadian Engineering Education Conf., CEEA13, (Montreal, PQ; 17-20 June 2013), 2013. 